\title{
Topic of Interest
}

\section{Primitive forcible contraception in sub-Saharan Africa}

\author{
Dr. Ozer Birge, ${ }^{1}$ Dr. Ilkan Kayar, ${ }^{2}$ Dr. Alparslan Merdin, ${ }^{1}$ Dr. Ertugrul Gazi Ozbey, ${ }^{1}$ \\ Dr. Mehmet Adiyeke, ${ }^{3}$ Dr. Utku Akgor ${ }^{1}$
}

Keywords: Primitive, forcible contraception, sub-Saharan Africa

\begin{abstract}
A 33-year-old multiparous patient was admitted to our gynecology outpatient service with complaints of severe abdominal pain, vaginal bleeding, malodorous vaginal discharge, difficulty in sexual intercourse and difficulty in urination for the last one month. Hereby, we aimed to show this creative, brutal and primitive way of contraception in a local tribe in the Darfur region of sub-Saharan Africa.

${ }^{1}$ Department of Obstetrics and Gynecology, Nyala Sudan-Turkish Training and Research Hospital, West Alessa District, Nyala, Sudan ${ }^{2}$ Osmaniye State Hospital, Osmaniye, Turkey ${ }^{3}$ Bergama State Hospital, Department of Gynaecology and Obstetrics, Bergama, Turkey
\end{abstract}

\section{Background}

A 33-year-old multiparous patient was admitted to our gynecology outpatient service with complaints of severe abdominal pain, vaginal bleeding, malodorous vaginal discharge, difficulty in sexual intercourse and difficulty in urination for the last one month. Physical examination revealed a rusty wire that was inserted into the vaginal entrance which at first seemed like a piercing (Figure 1). But, vaginal inspection revealed a spiral rusty wire surrounding and enclosing the cervix of the uterus (Figure 2-3).

\section{Discussion}

It was revealed from the history that the woman was the first and older wife of her husband who also had one younger wife. Up to four marriages for husbands are common in sub-Saharan Africa and it is legal in the Darfur region. The younger wife was a tribal midwife, not educated and not legal. The patient claimed that the younger wife had given her some traditional plants which made her sleep and that the wire was inserted into her vagina while she was sleeping.

Please cite this paper as: Birge O, Kayar I, Merdin A, Ozbey EG, Adiyeke M, Akgor U. Primitive forcible contraception in sub-Saharan Africa. Proc Obstet Gynecol. 2015;5(3): Article 6 [ 2 p.]. Available from: http://ir.uiowa.edu/pog/ Free full text article.

Corresponding author: Ozer Birge, Department of Obstetrics and Gynecology, Nyala Sudan-Turkish Training and Research Hospital, West Alessa District, Nyala, Sudan, ozbirge@gmail.com

Financial Disclosure: The authors report no conflict of interest.

Copyright: (c) 2015 Birge et al. This is an open-access article distributed under the terms of the Creative Commons Attribution License, which permits unrestricted use, distribution, and reproduction in any medium, provided the original author and source are credited. 


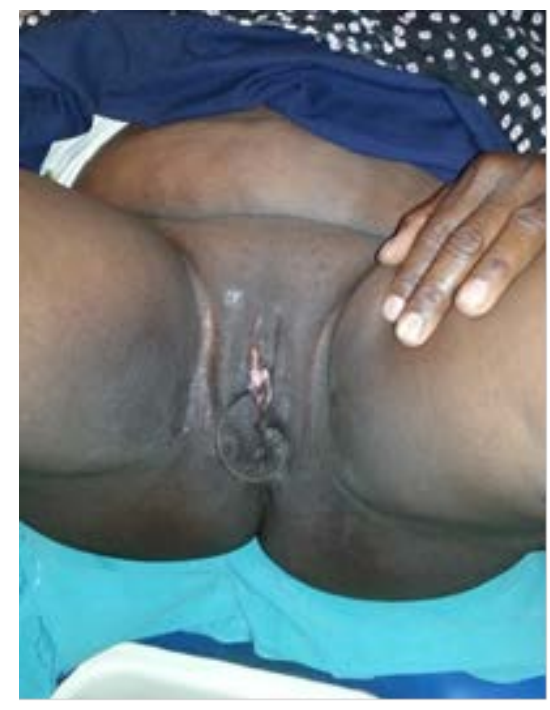

Figure 1

She reported that the younger wife did this to her because of jealousy and to prevent her from having sex and children with their husband. She also added that women without children could be shamed and divorced in their tribe. Lastly, she said that she had not been aware of the procedure until she woke up in the morning.

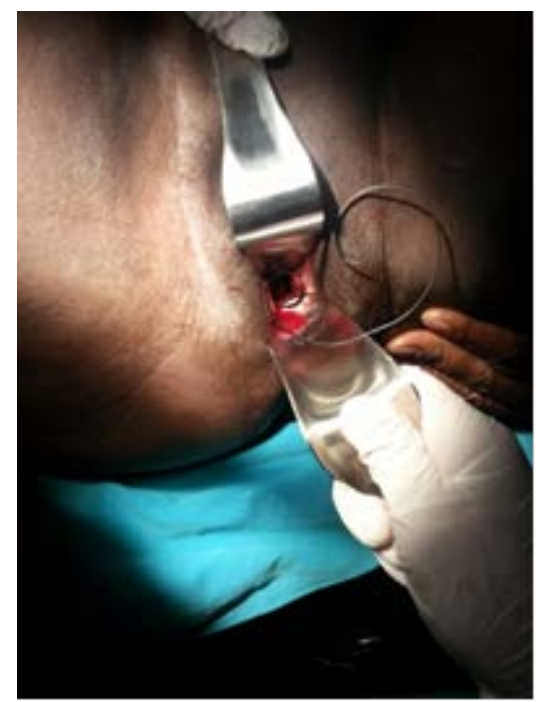

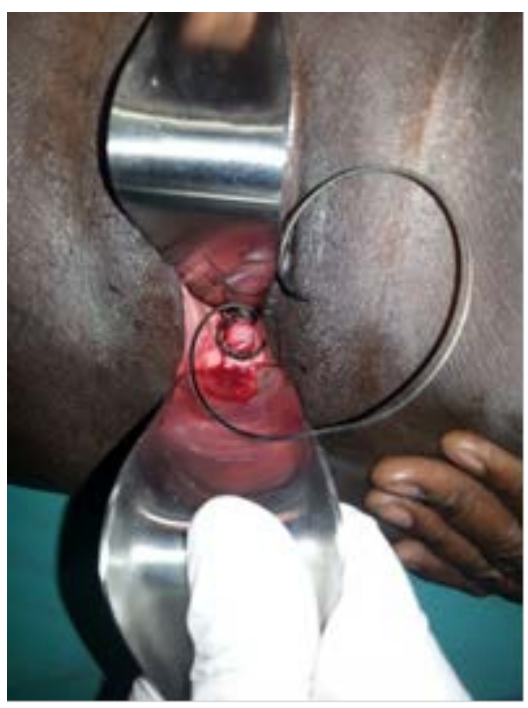

Figure 3

\section{Conclusion}

The fixated wire was removed with local anesthesia. Antibiotic therapy was started and tetanus vaccine was given. The patient had no more complaints in her outpatient controls. Hereby, we aimed to show this creative, brutal and primitive way of contraception in a local tribe in sub-Saharan Africa.

Figure 2 